\title{
Frontline Staff's Emotional Intelligence and Creativity Impact on Job Performance
}

\author{
Noor Maya Salleh \\ Institut Teknologi Brunei, \\ Brunei Darussalam
}

\author{
Shamsul Baharin Abdul Rahman \\ DST Communications Sdn Bhd, \\ Brunei Darussalam
}

\begin{abstract}
The relationships between EI (emotional intelligence) and creativity with the JP (job performance) of the frontline staff working in three sister companies were investigated. These groups' compensation benefit also served as a control variable by grouping them according to (1) DSTCom-Significant Revenue Contributor-High Compensations and Benefits; (2) Kristal-Insignificant Revenue Contributor-High Compensations and Benefits; and (3) Incomm - Significant Revenue Contributor-Low Compensation and Benefits. The mean EI, creativity, and JP measures of the three groups were compared. Some differences in the level of creativity between these three groups were found. High level of intelligence is positively related to high creativity which translated into the JP. The findings were discussed from the perspective of theoretical and practical implications.
\end{abstract}

Keywords: emotional intelligence, creativity, job performance

\section{Introduction}

Competing in today's cut-throat competitive environment is no longer about products and processes differentiation or advantages. More and more organisations are increasingly turning towards their employees for differentiation and competitive advantages. In business, human factors will always play a pivotal role in providing some sort of a connection between employees and customers. However, technical and analytic skills are not the only required skills for employees to be effective, well-developed emotional skills are also required for excellence (Guy \& Lee, 2013).

Product, price, location, promotion, or even technological solutions can never stoke the emotional connection between employees and customers. Beaujean, Davidson, and Madge (2006) in their study on some German banks found that, it is the emotional bond between customers and employees that creates customer loyalty rather than products or services or technological solutions. Therefore, when everything else is not working, organisations often found that it is the skills and competencies of employees along with an appropriate range of deep-seated emotional and psychological assumptions that will give them the competitive edge in the markets.

Tischler, Biberman, and McKeage (2002) believed that emotional and spirituality factors can play a significant role in promoting an individual's success at work. The working condition of a frontline employee is of an atmosphere where highly emotional discharge occurrence is more frequently experienced than a normal

Noor Maya Salleh, Ph.D., Institut Teknologi Brunei.

Shamsul Baharin Abdul Rahman, DST Communications Sdn Bhd. 
employee who is not facing customers. This is where employees would constantly experience emotional labour. Emotional labour is an act of managing emotions and emotional expressions in order to be consistent with the organisational display rules. Such rules are organisationally required during interpersonal service transactions. Should the display emotion is different with what the employee actually feels, an emotional dissonance occurred (Mikolajczak, Menil, \& Luminet, 2007). Although in the short-run emotional dissonance may affect JP (job performance) positively, in the long run it can lead to emotional exhaustion (Karatepe \& Uludag, 2008). Emotional exhaustion has been found to be negatively affecting JP. Emotional exhaustion is caused by employees inability to handle the emotional impacts experienced while performing their jobs (Halbesleben \& Bowler, 2007). Kiely (2005) in discussing emotional labour concluded that emotional sensitivity is more effective dealing with customers as such emotion is more genuine than emotion expressed in emotional labour. Service relationship between customers and frontline staff is characterised by mutual trust and cooperation. This is significant as customers evaluations of service usually correlate highly with their displayed emotions during transaction (Mattila \& Enz, 2002). This is where an employee's emotional stability played a significant role. Emotional stability which has also been found to be a generalisable predictor of overall JP can normally be found within individuals with high EI (emotional intelligence) (Barrick, Mount, \& Judge, 2001).

In fact, emotional is found to be a desirable problem-solving skill that can resolve many workplace problems such as bullying (Sheehan, 1999). Researchers like Zeidner, Matthews, and Roberts (2004) have also successfully demonstrates through their works the importance of EI in promoting occupational environment that led to better JP. Such works convinced many others that EI is a necessary skill in identifying opportunities to improve customer experience and company performance. Ultimately, EI has become an important factor in organisations today due to its growing reputation as a determinant of positive working behaviours (Lassk \& Shepperd, 2013; Salleh, 2010; Aqayar \& Sharifi, 2007).

More competitive economy has also stacked the deck against organisational creativity (Thompson, 2003). Importance of creativity has long been argued at individual and organisational levels (Paulus, 2000). Creative individuals create innovative organisations. Innovative organisations usually produced strong business performance (Hult, Hurley, \& Knight, 2004). In addition, being creative can improve organisational performance such as planning, implementation and control (Barret, Balloun, \& Weinstein, 2005).

Evidence suggests that individual's behaviour at work may play a somewhat a larger role in the business success in general. Employees are therefore expected to play a vital role for organisations through their performance, learning, development, creativity, and innovative ideas (Van der Sluis, 2007). Similarly, Shalley and Gibson (2004) suggested that due to increasing competition and unpredictable technological changes, managers need to be more active in encouraging employees to be more creative which can enhance innovation. In practice, global companies in Korea for example have adopted various strategies to stimulate employees creativity to gain innovative-based competitive advantage in the market (Sohn \& Jung, 2010).

Creative frontline employees can be crucial in the performance of the employees' jobs. In fact, employee creativity has been identified as a key variable in generating an organisation's competitive advantage (Shalley, Zhou, \& Oldham, 2004). The potential creativity of frontline service employees therefore holds an important role in promoting organisational innovation.

\section{Objectives}

There has been increasing focus on the academic investigation on the success stories of individuals at 
work as a result of their positive mood and emotion. Existing literatures refer organisations as emotional places because the core organisation of work concerns what employees do with their feelings. Emotional expression also becomes a key part of the work role. This gives rise to the concept of EI and its impact on the overall organisation.

Individuals high in EI are likely to persevere when problems arise and search for challenges and therefore challenging opportunities. Emotionally intelligent person may also show a higher degree of personal initiative and actively search for information (Wong \& Law, 2002; Mayer \& Salovey, 1997).

Evidence has been increasingly accumulating that EI is associated with important outcomes such as high quality social relationships (Lopes, Brackett, Nezlek, Schütz, Sellin, \& Salovey, 2004; Lopes, Salovey, Côté, Beers, \& Petty, 2005) but there is a paucity of research, however, on EI and workplace outcomes. Cumulative findings suggest that emotionally intelligent persons are better performers than their counterparts (Law et al., 2004; Van Rooy \& Viswesvaran, 2004), but little is known about how EI is related to outcomes such as salary and affect at work.

Meanwhile, scholars collectively have long expressed concern for lack of independent, systematic analysis substantiating the claim that EI increases JP (Lam \& Kirby, 2002; Wong \& Law, 2002; Amelang \& Steinmayer, 2006; Carmeli \& Josman, 2006; Shahzad, Sarmad, Abbas, \& Khan, 2011; Wu, 2011). Although they generally found specific EI abilities such as emotional perception and emotional regulation uniquely explained individual's cognitive-based performance more convincingly than general intelligence, the overall EI construct ability to predict success and achievement was rather inconsistent. More significantly, EI was found to be unable to explain the achievement beyond psychometric intelligence and conscience.

The main objective of this research is to identify the relationship between EI, creativity, JP at frontline environment workplace.

How training and development can contribute to strengthen the relationship between these variables is also given careful consideration. Dulewicz and Higgs (2004) found that EI can be developed to enhance performance. Boyatzis (2008) supported this finding through his work in emotional competencies development of a group of managers and leaders. Deeter-Schmelz and Sojka (2003) also agreed with the view that EI can be trained as a mean to improve performance. Meanwhile, Slaski and Cartwright (2003) has successfully proven that after EI training, a number of UK managers were able to handle stress which resulted in improved overall performance. However, even these researchers expressed concern about lack of empirical evidence of link between emotional competencies and performance.

Another one of the main sources of inspiration of this research is the burning desire to find out if creativity can compensate for the lack of EI in enhancing JP. Therefore, this study aim to test if by infusing creativity can enhance the JP among frontliners of varying level of EI. This study therefore seeks to identify the relationship between EI, creativity, and JP among employees in a private sector organisation in Brunei.

In Brunei, not so much works on EI has been done apart from the works of Clarke and Salleh (2011), Salleh and Clarke (2010), Salleh (2009) on EI currently available. A quick search on the creativity and JP researches within Bruneian context showed that such studies currently are practically non-existent. Therefore, it is hoped this study is one of the first of many to rectify that situation. This will be a breakthrough research since no study so far has been conducted to seek the relationship between these variables in the Bruneian context. 


\section{Literature Review}

EI

The most scientifically accepted version of EI definition is "the ability to monitor one's own and others' emotion, to discriminate among them, and to use the information to guide one's thinking and actions" by Salovey and Mayer (1989). This definition identifies emotion information processing as a necessary precursor to emotion regulation and thus argued by some as the most workable contemporary definition of EI (Matthews, Zeidner, \& Roberts, 2004).

Binet, Thorndike, and Gardner have been identified as the pioneers of studies on intelligence. It all started when Binet, Simon, and Town (1913) developed adult intelligence concept as a mean to measure cognitive abilities. This has eventually led to the development of IQ (Intelligence Quotient) measures. Thorndike (1920) subsequently developed the concept of social intelligence as a means to explain the variance in outcome measures not accounted for by IQ. However, social intelligence as a construct was difficult to conceptualise and therefore never managed to developed a reliable measure to support it. Gardner and Hatch (1989) further developed the term multiple intelligences for a similar reason. However, they were unable to find any significant relationship between multiple intelligence and IQ measures. This led to the conclusion that there was an "other" intelligence which was a distinctly different construct from the IQ (Dulewicz \& Higgs, 2000).

Later, Salovey and Mayer (1990) explicitly defined the construct and developed the EI theory and demonstrated the measurement of EI. EI concept is thus defined as a set of individual abilities, specifically as a learned ability to perceive, understand and express our feelings accurately and to control our emotions so that they work for us, and not against us (Mayer \& Salovey, 1997). Their definition viewed EI as a type of social intelligence that involves the ability to monitor one's own and other's feelings and emotions, to discriminate among them and to use this information to guide one's thinking and action.

According to Mayer and Salovey (1997), ability-based EI model, there are four abilities identified namely perceiving emotions, using emotions, understanding emotions and managing emotions. The first ability is to detect and decipher emotions in faces, pictures, voices, and cultural artefacts including identification of own emotions. The second ability is the use of emotions where one should be able to harness emotions to facilitate various cognitive activities such as problem-solving. It is argued here that one should capitalise on his or her changing moods to best fit task at hand. The third ability is the understanding of emotions through understanding emotion language and appreciates complicated relationships among people thus showing sensitivity to others. The fourth and final ability is the ability to regulate emotions in both ourselves and others. An emotionally intelligent person can harness even negative emotions in others and manage them to achieve intended goals.

The present study was based on Mayer and Salovey's (1997) theory of EI, viewed as a set of four interrelated abilities involved in the processing of emotional information. The ability to perceive emotions in oneself and others entails identifying internal cues of emotional experience and emotional information in facial expressions, voice, music, designs, and other stimuli. The ability to use emotions to facilitate thinking entails integrating emotional information with cognitive processes. The ability to understand emotions entails appreciating emotional dynamics and blends of emotions and how these influence thinking and behaviour. The ability to manage emotions entails regulating emotional experience in oneself and in interpersonal situations to attain personal goals and adaptive outcomes. 
There have also been many seminal writings on EI that examining its implication on individual well-being and life outcomes, job satisfaction, work performance, and leadership (Salleh, 2010). Several studies have also concluded that EI is particularly important in apprehending and managing stress (Salleh, 2010; Clarke \& Salleh, 2011). Those who are able to manage their stress well are able to bring positive energy to their surroundings.

To be emotionally intelligent, one needs to understand how others feel and know how to manage them therefore improving and maintaining good relationships with others. By being emotionally intelligent also means that employees can influence their actions and also influence others towards more positive actions at work (Xavier, 2005). This would require organisations to develop managers who are leaders of people and not managers of processes (Kotter, 2006).

The rising importance for employees to be emotionally intelligent at work has strong implications towards HRD (human resources developments) in organisations. Therefore, there is a need to develop managers who are able to manage the value chain that starts with employee investment that drives customer loyalty and ultimately shareholder value. Consequently, all employees must also be developed by these managers through attending to their EI and HRD that impacted the organisational performance. Therefore, leaders should design HRD that take cognisance of developing both management and employees' EI and social networks. By having management and employees who are highly competent emotionally, poor performance can be addressed more objectively (Chirasha, 2008; 2013). Ultimately employees, while receiving coaching and guidance from the managers would need to apply their own EI and help develop social networks that would benefit the organisation. Such development should be possible given the fact that studies by Salleh (2009), Salleh and Clarke (2010), and Clarke and Salleh (2011) has strongly indicated that EI can be developed and increased through training.

\section{Creativity}

Creativity as a variable is a highly ambiguous concept that tends to be defined differently depending on the field of study it is related (Runco, 2004). It is a decades-long fact that there is no single authoritative definition of creativity as well there is no standardised measurement technique or agreed upon set of valid measures. Antonite (2003) stated that there were more than 100 definitions of creativity and that figure has continued to go up until today. Attempts were made to develop a CQ (Creativity Quotient) of an individual like the IQ but they were unsuccessful (Plucker \& Renzulli, 1999). It has long been accepted development of standardised measure for creativity is too problematic to develop. This is largely due to lack of objectivity is assessing the creativity concept by researchers. The key factor in this rift is domain generality-specificity approach issue main question, what it means to be creative.

However, the one common ground generally agreed by scholars about creativity is that it must involve the production of something that is new and useful (Mumford, 2003). Creativity has been defined as the generation of novel and useful ideas (Amabile, 1988) and serve as a function of employees' dispositional characteristics, contextual factors, and the interaction between these factors (Amabile, 1996). Currently, Amabile's definition of creativity is the most accepted version in the field of research and therefore this study will be based on this version.

Various researches had indicated that some level of creativity is needed in the almost any type of job (Unsworth, 2001; Shalley \& Gibson, 2004). Therefore, there were indications that creativity can fundamentally contribute towards organisational innovativeness, effectiveness, and survival (Amabile, 1996; Shalley et al., 
2004; Zhang \& Bartol, 2010). In order to remain relevant and to compete, the organisations must generate creative ideas frequently and utilise innovative processes to fully-realise the values of those ideas (McLean, 2005). Such findings and opinions have contributed towards the new interest in organisations trying to find methods to encourage and enhance creativity at work through HR (human resources) and HRD measures.

JP

Just like EI and creativity, the concept of JP has been receiving a considerable scholarly attention over the past decade or so. Similarly with creativity, it is a difficult construct to generalise. The word "performance" is used frequently in companies, among human resources departments and in industrial psychology and management yet despite its obvious importance and popularity, it is seldom clearly defined (Neely, Gregory, \& Platts, 1995).

It is generally agreed that JP has to be considered and viewed as a multi-dimensional concept. Basically JP can be set apart through process aspect and outcome aspect. The process aspect, also known as the behavioural aspect, refers to what people do while at work. Such action may include specific behaviour such as serving a customer, repairing a car or cooking for a party. The outcome aspect refers to the result of the person's behaviour or action. Such results may include in creating a happy and loyal customer, a good-for-the-road car or delicious food that made party-goers smile. However, since the outcome aspect is always affected by other determinants, some scholars suggest that JP needs to be differentiated from effectiveness and efficiency. This is due to possibility of situations such as where an employee's effort to repair a car may not result in a car being capable of running on the road again.

Perhaps more importantly, researchers such as Borman and Motowidlo (1997) have generally agreed that distinction between task performance and contextual performance must also be identified. Task performance which covers an employee's contribution to the organisation's performance refers to actions that are part of the formal reward system and addresses the requirement as specified in an employee's job description (Williams \& Karau, 1991). Task performance covers the fulfilment of the requirements that are part of the contract between the employer and employee. Contextual performance includes activities that are not formally part of the employee's job description. Therefore, it is different from task performance. However, it indirectly contributes to an organisation's performance by facilitating task performance. These may include putting extra efforts, assisting colleagues at work, complying with organisation's rules and regulations. Therefore, contextual is multidimensional in nature rather than a single set of uniform behaviours (Van Dyne \& LePine, 1998). Later, scholars such as Pulakos, Arad, Donovan, and Plamondon (2000) added adaptive performance as another type of JP that needs to be identified as a separate performance variable. They proposed an eight-dimensional taxonomy of adaptive performance that include handling emergencies, handling stress, creative problem-solving, dealing with ambiguity, learning, demonstrating adaptability, demonstrating cultural adaptability and demonstrating physically oriented adaptability. Just like task and contextual performance, adaptive performance is a multi-dimensional construct and existed across many types of jobs.

JP is also usually described in terms of observable and non-observable behaviours which can be appraised (Viswesvaran, Schmidt, \& Ones, 2005). It is a multidimensional concept which describes how one completes a task, focusing on efficiency, skills used, initiative, and utilised resources (Rothmann \& Coetzer, 2003). JP is an action that involves process and product (final output). The individual process can be influenced by an organisation's overall performance. It is not only actions that determine one's performance but also external 
factors such as resources, organisational culture and economic, political, and social factors (Porter, 2005).

According to Viswesvaran $(2001 ; 1993)$, JP consists of 10 dimensions. Depending on the nature of the job, certain dimensions are more important than others. The dimensions include, overall performance, productivity, communication, effort, job-related knowledge, interpersonal skills, quality, leadership, rule following, and administrative skills. Those dimensions mostly overlap with the eight dimensions highlighted by Campbell, McCloy, Oppler, and Sager (1993) and which are generally well accepted.

On the other hand, Campbell et al. (1993) suggested that JP has eight dimensions. They identified JP to be a combination of job-specific task proficiency, non-job-specific proficiency, written and oral communication, demonstrating effort, maintaining personal discipline, facilitating peer and team performance, supervision/leadership, and management/administrative.

From the perspective of Ivancevich, Konopaske, and Matteson (2005), the following three main factors impact on performance are willingness to perform (motivation), opportunity (organisational factors such as resources and tasks) and finally the capacity to perform (skills, abilities and knowledge). Grote (2002) explained work performance from a behavioural perspective. By concentrating on work-related observable activities, one is able to evaluate JP more objectively, thus eliminating rating bias. This is only achievable in an environment in which, the outputs and criteria are clearly defined.

The interest of this study however is from the perspective of how the JPs of the frontliners are viewed personally by the employees themselves. Therefore, what definition of JP that needed to be adopted is not actually concluded in this study. But while this has not been emphasized formally in this study, it should be noted the frontliners' JP has a direct impact on the satisfaction of the customers due to being the interaction point between the organisation and the customers (Hartline, Maxham, \& McKee, 2000) and, it is therefore imperative for JP to be assessed accordingly even using a self-report instrument as customers often based their impressions of the firm largely on the service that was received from the frontliners.

\section{The Relationship Between EI and Creativity With JP}

Although few topics in the world of organisational behaviour is as controversial or as dividing as EI, yet more and more scholars and practitioners are convinced that as a concept EI is a valid predictor of many outcomes in all areas of life. Today, the concept of EI has significantly emerged as an important predictor of work-related behaviours. This has led to scholars study if EI is conceptually relevant in predicting JP due to organisations requiring interpersonal interactions to accomplish goals, and most jobs require the ability to manage emotions (Shahzad, Sarmad, Abbas, \& Khan, 2011).

EI may contribute to JP as reflected performance appraisal, pay increase, promotion and other recognitions. This can achieved by enabling people to build positive relationships at work, work effectively in teams, and build social capital. JP often depends on the support, advice, and other resources provided by others (Seibert, Kraimer, \& Liden, 2001). EI may also contribute to JP by enabling people to regulate their emotions so as to cope effectively with stress, perform well under pressure, and adjust to organisational change.

Rosete and Ciorrachi (2005) for example, have successfully established the fact that EI has a strong positive relationship to workplace performance outcomes of leadership effectiveness. Meanwhile, Ashkanasy and Daus (2005) have identified EI as a key element of an employee's competence. EI is also strongly considered as a feasible variable in explaining success at not only work but life in general Liptak (2005). More importantly, some researchers believe that it is a strong potential in predicting an employee's JP (Jacques, 
2009).

However, it is important for organisations to identify with different level of EI that exist within individuals. This is because employees with different level of EI abilities may use different strategies in coping with emotional dissonance. High level emotional intelligent employees normally experience lower level of burnout mediated by choice of labour strategies Mikolajczak, Menil, and Luminet (2007).

Therefore, by dividing the frontline employees according to their respective companies which act as a control variable, the following hypothesis is proposed:

Hypothesis 1a: There is a significant difference in the level of EI between the three companies frontline staff.

Researchers such as Suh and Shin (2005) have suggested that to test the relationship between creativity and JP, it is very important for researchers to place an emphasis on environmental differences. Their own study indicated that there were differences in the level of relationship between creativity and JP between profit-driven organisations with non-profit organisations. This theory was supported by Martinaityte and Sacramento (2012) who found the more creative sales agents in the pharmaceutical and insurance fields generated higher sales performance but only when they have high quality leader-member exchange.

Organisational climate and structure variables may influence the staff's level of creativity at work (Ekvall, 1997). Work environments therefore complementd the creative requirements of the employees jobs (Shalley et al., 2000). Therefore, by grouping the employees into three main groups differentiated by their revenue contribution and benefits received in return is aimed at finding out such difference and the following hypothesis is proposed:

Hypothesis $1 \mathrm{~b}$ : There is a significant difference in the level of creativity between the three companies frontline staff.

Hypothesis 1c: There is a significant difference in the level of JP between the three companies frontline staff.

According to Wu (2011), EI can directly or indirectly impact performance. Such view was supported by Shahosseini et al. (2012) who also found EI can impact individual and overall organisational performance in a variety of ways. Earlier works by Rode et al. (2007) suggested that effects of EI are more indirect than direct in nature. They further concluded that to perform, individuals must not only have EI but must be motivated to use it. Fisher and Ashkanasy (2000) also indicated such view by demonstrating that stress can affect the incremental validity of EI effect on JP.

Currently, a quick search on some scholarly online libraries, databases and search engines revealed a severe lack of studies on the relationship between creativity at work and JP. Nonetheless, there are several research studies that indicate positive relationships between team performance and creativity. Such a work by Guzzo and Dickson (1996) showed evidence that team effectiveness is well-served by when teams perform cognitive, creativity-demanding tasks.

Most creativity is found in creative pursuits undertaken for the sake of the activity itself, and not for the sake of some other end (Amabile et al., 1990; Amabile \& Hennessey, 1992; Conti, Amabile, \& Pollack, 1995). Meanwhile, EI has been found to develop innovational creativity in individual and as a result helps in the improvement of the people's JP (Ganji, 2011; Hasanzadeh, 2009). Therefore, in this study we will examine the relationship of creativity and team performance of auditor in tandem with EI.

Hypothesis 2: Creativity can significantly predict JP. 
Numerous authors have theorised that EI contributes to people's capacity to work effectively in teams and manage work stress such as Caruso and Salovey (2004) and Goleman (1998). Yet, empirical research has lagged behind both media hype and academic interest, and many critics like Matthews et al. (2004; 2007); Zeidner et al. $(2004 ; 2008)$ have lamented the lack of solid empirical evidence showing that EI is related to positive workplace outcomes.

Nevertheless, Cherniss (2001) through his works on the US Air Force workforce, suggested EI can predict JP and satisfaction. When an organisation evaluates the EI of its employees and of its star performers, it gains a strong blueprint for improving individual performance, enhancing the workplace climate and driving productivity. By targeting recruits who scored high EI test marks, the US Air Force increased their retention rate to $92 \%$ saving an amount of $\$ 2.7$ million in labour turnover expenses. The high EI recruits were also calculated to be 2.7 times more likely to succeed. High EI workers are more apt in ommunicating internally under different and stressful environment. It has been identified that breakdowns in internal communication that produce confusion, uncertainty, hostility and reduced productivity. The goal of the present study was to test theoretical associations between EI and work performance.

Sy, Tram, and O' Hara's (2006) study on fast food employees of a franchise restaurant showed that the managers and crews' EI was positively associated with job satisfaction and JP. More significantly, a meta-analysis using the three main streams of EI construct by Day and Carroll (2004) support the validity of EI in predicting JP.

Hypothesis 3: EI can significantly predict JP.

\section{Methods}

A total of 120 questionnaires were distributed amongst the employees of the three sister companies. This figure amounted to about $20 \%$ of the combined total number of employees of the theree companies. Half of the non-respondents were from DSTCom while the other half was split equally between Kristal and Incomm A total of 100 questionnaires were completed and returned. From the overall participants, 58 (58\%) of them were female. This is just about in line in comparison to the DST's composition of 5.5:4.5 female: male ratio. On a national level the ratio of female: Male workforce ratio is closer towards 50:50 ratios. 60 individuals $(60 \%)$ of the participants worked for DSTCom, 21 individuals (21\%) worked for Kristal while 19 individuals (19\%) worked for Incomm.

Three instruments were administered to assess EI, creativity, and JP. EI was measured using a validated instrument WLEIS (Wong and Law's EI Scale). The WLEIS (Cronbach alpha 0.89) was designed as a short measure of EI for use in organisational research. It is a self-report EI measure developed for Chinese respondent (Wong \& Law, 2002) and comprises 16 items, responded to on a 7-point Likert scale. WEIS is a scale based on the four ability dimensions described in the domain of EI including: (1) appraisal and expression of emotion in the self; (2) appraisal and recognition of emotion in others; (3) regulation of emotion in the self; and (4) use of emotion to facilitate performance. Coefficient alphas for each of these domains were $0.69,0.84$, 0.78 , and 0.72 respectively. This measurement was used due to its development background which was based on the Asian culture which to some extent has similar context to Brunei. Wong and Law (2002) also report good internal consistency reliabilities for their measure. In terms of validity, they present data showing that scores on the WLEIS are related to JP and job satisfaction. A sample item from this measure is "I have a good sense of why I have certain feelings most of the time". 
The creativity was measured using Zhou and George's (2001) 13-items. This instrument has a coefficient alpha of 0.88. This measure is consistent with Amabile's (1988) view of creativity where this scale measure creativity as a two-dimensional constructs comprising of new or useful ideas. An example of a useful idea item is "I come up with creative solutions to problems". On the other hand, a sample of the new idea item is "I suggest new ways to increase quality".

JP was measured using Babin and Boles (1998) six-items self-report instrument. This five Likert-scale measuring tool has a cronbach alpha of 0.88 .

\section{Results}

Hypothesis 1 was tested using one-way ANOVA test. Table 1 indicated that overall each of the variables in this study has a high mean either for each individual company or combined. The combined mean for all companies on EI is 5.56. As for creativity the combined mean is 3.46 while for JP it is 3.62 .

Table 1

Mean, Standard Deviation, and Standard Error

\begin{tabular}{llrlll}
\hline & & $N$ & Mean & Std. Deviation & Std. Error \\
\hline \multirow{3}{*}{ JP } & DSTCom & 59 & 3.6859 & 0.51020 & 0.06642 \\
& Kristal & 22 & 3.6436 & 0.52011 & 0.11089 \\
& Incomm & 19 & 3.4037 & 0.51905 & 0.11908 \\
& Total & 100 & 3.6230 & 0.52014 & 0.05201 \\
\multirow{4}{*}{ Creativity } & DSTCom & 59 & 3.4312 & 0.56998 & 0.07420 \\
& Kristal & 22 & 3.6718 & 0.47990 & 0.10231 \\
& Incomm & 19 & 3.3200 & 0.58568 & 0.13436 \\
& Total & 100 & 3.4630 & 0.56193 & 0.05619 \\
EI & DSTCom & 59 & 5.6088 & 0.71013 & 0.09245 \\
& Kristal & 22 & 5.8364 & 0.79146 & 0.16874 \\
& Incomm & 19 & 5.0905 & 0.85159 & 0.19537 \\
\hline
\end{tabular}

The results for the test of homogeneity of variance (see Table 2) were positive with each of the variable high significance value. The significance value of EI, creativity and JP was indicated at $0.906,0.681$, and 0.302 respectively.

Table 2

Test of Homogeneity of Variances

\begin{tabular}{lllll}
\hline & Levene Statistic & $d f 1$ & $d f 2$ & Sig. \\
\hline JP & 0.099 & 2 & 97 & 0.906 \\
Creativity & 0.386 & 2 & 97 & 0.681 \\
EI & 1.213 & 2 & 97 & 0.302 \\
\hline
\end{tabular}

The ANOVA table (see Table 3) indicated that there was significant difference in the level of EI between the groups, $F(2,97)=5.26, p=0.007$. However the same cannot be said for the other two variables. There was no significant difference in the level of creativity between the groups, $F(2,97)=2.29, p=1.07$ while for JP there was also no significant difference in the level of JP between groups, $F(2,97)=2.19, p=$ 0.117 . 
Table 3

ANOVA

\begin{tabular}{llrrlll}
\hline & & Sum of squares & $d f$ & Mean square & $F$ & Sig. \\
\hline \multirow{3}{*}{ JP } & Between groups & 1.157 & 2 & 0.578 & 2.189 & 0.117 \\
& Within groups & 25.628 & 97 & 0.264 & & \\
& Total & 26.785 & 99 & & & 0.107 \\
\multirow{4}{*}{ Creativity } & Between groups & 1.408 & 2 & 0.704 & 2.287 & 0.007 \\
& Within groups & 29.853 & 97 & 0.308 & & \\
& Total & 31.261 & 99 & & & \\
& Between groups & 6.009 & 2 & 3.004 & & \\
& Within groups & 55.457 & 97 & 0.572 & & \\
\hline
\end{tabular}

On the other hand, our post hoc tests table (see Table 4) showed that it is the Incomm group that differ significantly from both DSTCom and Kristal in term of the level of EI with a significance value of 0.029 and 0.006 respectively.

Table 4

Post Hoc Tests

\begin{tabular}{|c|c|c|c|c|c|}
\hline Dependent variable & (I) Company & (J) Company & Mean difference (I-J) & Std. error & Sig. \\
\hline \multirow{6}{*}{ JP } & \multirow{2}{*}{ DSTCom } & Kristal & 0.04230 & 0.12840 & 0.942 \\
\hline & & Incomm & 0.28225 & 0.13559 & 0.099 \\
\hline & \multirow{2}{*}{ Kristal } & DSTCom & -0.04230 & 0.12840 & 0.942 \\
\hline & & Incomm & 0.23995 & 0.16098 & 0.300 \\
\hline & \multirow{2}{*}{ Incomm } & DSTCom & -0.28225 & 0.13559 & 0.099 \\
\hline & & Kristal & -0.23995 & 0.16098 & 0.300 \\
\hline \multirow{6}{*}{ Creativity } & \multirow{2}{*}{ DSTCom } & Kristal & -0.24063 & 0.13858 & 0.197 \\
\hline & & Incomm & 0.11119 & 0.14634 & 0.728 \\
\hline & \multirow{2}{*}{ Kristal } & DSTCom & 0.24063 & 0.13858 & 0.197 \\
\hline & & Incomm & 0.35182 & 0.17375 & 0.112 \\
\hline & \multirow{2}{*}{ Incomm } & DSTCom & -0.11119 & 0.14634 & 0.728 \\
\hline & & Kristal & -0.35182 & 0.17375 & 0.112 \\
\hline \multirow{6}{*}{ EI } & \multirow{2}{*}{ DSTCom } & Kristal & -0.22755 & 0.18888 & 0.453 \\
\hline & & Incomm & 0.51829 & 0.19945 & 0.029 \\
\hline & \multirow{2}{*}{ Kristal } & DSTCom & 0.22755 & 0.18888 & 0.453 \\
\hline & & Incomm & 0.74584 & 0.23681 & 0.006 \\
\hline & \multirow{2}{*}{ Incomm } & DSTCom & -0.51829 & 0.19945 & 0.029 \\
\hline & & Kristal & -0.74584 & 0.23681 & 0.006 \\
\hline
\end{tabular}

Note. The mean difference is significant at the 0.05 level.

Meanwhile hierarchical regression was used to test hypotheses 2 and 3. A three-step analysis was conducted with JP as the dependent variable. The group of companies were entered first as a control variable. Creativity was entered at stage two and the third final step was the inclusion of EI. The variables were entered in this order as it is considered to be chronologically sensible given that EI is best tested in tandem with another independent variable as a predictor of the dependent variable.

The coefficient table (see Table 5) showed that there is no existence of multicollinearity due to the tolerance value is more than 0.10 while the value of Variance Inflation Factor is below 10. Therefore, there is no need to remove any of the independent variables. 
Table 5

\section{Coefficientsa}

\begin{tabular}{|c|c|c|c|c|c|c|c|c|}
\hline \multirow{2}{*}{\multicolumn{2}{|c|}{ Model }} & \multicolumn{2}{|c|}{ Unstandardized coefficients } & \multirow{2}{*}{$\begin{array}{l}\text { Standardized coefficients } \\
\text { Beta }\end{array}$} & & \multirow{2}{*}{ Sig. } & \multicolumn{2}{|c|}{ Collinearity statistics } \\
\hline & & $B$ & Std. Error & & & & Tolerance & VIF \\
\hline \multirow{3}{*}{1} & (Constant) & 3.826 & 0.116 & & 32.939 & 0.000 & & \\
\hline & Company & -0.127 & 0.065 & -0.193 & -1.951 & 0.054 & 1.000 & 1.000 \\
\hline & (Constant) & 2.354 & 0.303 & & 7.776 & 0.000 & & \\
\hline \multirow[t]{3}{*}{2} & Company & -0.121 & 0.058 & -0.185 & -2.094 & 0.039 & 1.000 & 1.000 \\
\hline & Creativity & 0.423 & 0.082 & 0.457 & 5.177 & 0.000 & 1.000 & 1.000 \\
\hline & (Constant) & 1.890 & 0.383 & & 4.935 & 0.000 & & \\
\hline \multirow{3}{*}{3} & Company & -0.098 & 0.058 & -0.149 & -1.681 & 0.096 & 0.958 & 1.044 \\
\hline & Creativity & 0.341 & 0.091 & 0.368 & 3.746 & 0.000 & 0.783 & 1.277 \\
\hline & EI & 0.128 & 0.066 & 0.193 & 1.933 & 0.056 & 0.755 & 1.325 \\
\hline
\end{tabular}

The model was further evaluated by checking the model summary table (see Table 6). The first block explained $3.7 \%$ of the variance in JP. After block 2 variable of creativity was included, the model as a whole explained $24.6 \%$ of variance in JP. The third and final block when EI was included resulted in the model as a whole was explained $27.4 \%$ of variance in the dependent variable. As indicated in the $R$-Squared Change, creativity explained an additional $20.9 \%$ of the variance in the JP. EI on the other hand only explained an additional $2.8 \%$ of the variance in the outcome variable. However, only creativity is a significant contribution as a indicated by Sig. F-Change value of 0.000 .

Table 6

Model Summary

\begin{tabular}{|c|c|c|c|c|c|c|c|c|c|}
\hline \multirow[b]{2}{*}{ Model } & \multirow[b]{2}{*}{$R$} & \multirow[b]{2}{*}{$R$-Square } & \multirow{2}{*}{$\begin{array}{l}\text { Adjusted } \\
R \text {-Square }\end{array}$} & \multirow{2}{*}{$\begin{array}{l}\text { Std. Error of the } \\
\text { Estimate }\end{array}$} & \multicolumn{5}{|c|}{ Change Statistics } \\
\hline & & & & & $\begin{array}{l}R \text {-Square } \\
\text { Change }\end{array}$ & $F$-Change & $d f 1$ & $d f 2$ & Sig. $F$-Change \\
\hline 1 & 0.193 & 0.037 & 0.028 & 0.51292 & 0.037 & 3.807 & 1 & 98 & 0.054 \\
\hline 2 & 0.496 & 0.246 & 0.230 & 0.45635 & 0.208 & 26.804 & 1 & 97 & 0.000 \\
\hline 3 & 0.523 & 0.274 & 0.251 & 0.45005 & 0.028 & 3.736 & 1 & 96 & 0.056 \\
\hline
\end{tabular}

The ANOVA table (see Table 7) indicates that the model as a whole is significant. Model 2 and model 3 both indicated that the relationships are significant but the control variable in model 1 did not indicate any significance. The final model is shown as $F(3,96)=12.1, p<0.005$.

Table 7

\begin{tabular}{|c|c|c|c|c|c|c|}
\hline Model & & Sum of Squares & $d f$ & Mean Square & $F$ & Sig. \\
\hline \multirow{3}{*}{1} & Regression & 1.002 & 1 & 1.002 & 3.807 & 0.054 \\
\hline & Residual & 25.783 & 98 & 0.263 & & \\
\hline & Total & 26.785 & 99 & & & \\
\hline \multirow{3}{*}{2} & Regression & 6.584 & 2 & 3.292 & 15.806 & 0.000 \\
\hline & Residual & 20.201 & 97 & 0.208 & & \\
\hline & Total & 26.785 & 99 & & & \\
\hline \multirow{3}{*}{3} & Regression & 7.340 & 3 & 2.447 & 12.080 & 0.000 \\
\hline & Residual & 19.444 & 96 & 0.203 & & \\
\hline & Total & 26.785 & 99 & & & \\
\hline
\end{tabular}


Evaluation of each of the independent variable in the coefficients table indicated that EI did not make a unique significant contribution to the model due to it is high $p$-value of $(p>0.05)$. Creativity was shown as a good predictor of JP with a $\beta=0.37$ with $p<0.005$.

\section{Discussion}

Overall the current study has given mixed results with regards to the proposed hypotheses. Some of the hypothesis was supported while the others were not.

Interestingly, there was a significant difference in the level of EI of the frontline employees of Incomm, the high-performing but underprivileged company, with those of Kristal and DSTCom. But there was no significant differences of creativity and JP between any of these companies.

In terms of relationships, only creativity demonstrated significance as a valid predictor of JP while EI was not.

This evidence further adds to the academic literatures where EI were thought to be not a good predictor variable on its own and rather useful to be used in tandem with other variables in predicting outcomes. Therefore this study has contributed in strengthening the claim of scholars like Wu (2011) and Rode et al. (2007) who came to the opinion that EI is more likely to influence outcomes indirectly.

\section{Future Recommendation}

Future studies should consider the potential moderating and mediating impact of job environments in considering how EI and creativity predict JP. It would be useful if any such future researchers should also try to use different organisations within the same industry as well as organisations of different industries to lend more variety in term of population samples.

Different measuring instruments should also be considered in order to test and compare the significant findings derived from the utilisation of different methodologies employed to collect data.

\section{References}

Amabile, T. M. (1988). A model of creativity and innovation in organizations. In B. M. Staw, \& L. L. Cummings (Eds.), Research in organizational behavior (ol. 10, pp. 123-167). Greenwich, C.T.: JAI Press.

Amabile, T. M. (1996). Creativity and innovation in organizations (pp. 1-15). Harvard Business School.

Amabile, T. M., Goldfarb, P., \& Brackfleld, S. C. (1990). Social influences on creativity: Evaluation, coaction, and surveillance. Creativity Research Journal, 3(1), 6-21.

Amabile, T. M., \& Hennessey, B. A. (1992). The motivation for creativity in children. Achievement and Motivation: A Social-developmental Perspective, 54.

Amabile, T. M., Barsade, S. G., Mueller, J. S., \& Staw, B. M. (2005). Affect and creativity at work. Administrative Science Quarterly, 50(3), 367-403.

Amelang, M., \& Steinmayr, R. (2006). Is there a validity increment for tests of EI in explaining the variance of performance criteria?. Intelligence, 34(5), 459-468.

Antonites, A. J. (2003). An action learning approach to entrepreneurial creativity, innovation and opportunity finding (Doctoral dissertation, University of Pretoria).

Aqayar, S., \& Sharifi, P. (2007). EI (application of intelligence in emotion field) (2nd ed.). Tehran: Sepahan Publications.

Ashkanasy, N. M., \& Daus, C. S. (2005). Rumors of the death of EI in organizational behavior are vastly exaggerated. Journal of Organizational Behavior, 26(4), 441-452.

Babin, B. J., \& Boles, J. S. (1998). Employee behavior in a service environment: a model and test of potential differences between men and women. The Journal of Marketing, 62(2), 77-91.

Barrett, H., Balloun, J. L., \& Weinstein, A. (2005). The impact of creativity on performance in non-profits. International Journal of Nonprofit and Voluntary Sector Marketing, 10(4), 213-223. 
Barrick, M. R., Mount, M. K., \& Judge, T. A. (2001). Personality and performance at the beginning of the new millennium: What do we know and where do we go next?. International Journal of Selection and Assessment, 9(1-2), 9-30.

Beaujean, M., Davidson, J., \& Madge, S. (2006). The "moment of truth" in customer service. McKinsey Quarterly, 1, $62-73$.

Binet, A., Simon, T., \& Town, C. H. (1913). A method of measuring the development of the intelligence of young children. Courier.

Borman, W. C., \& Motowidlo, S. J. (1997). Task performance and contextual performance: The meaning for personnel selection research. Human performance, 10(2), 99-109.

Boyatzis, R. E. (2008). Competencies in the 21 st century. Journal of Management Development, 27(1), 5-12.

Campbell, J. P., McCloy, R. A., Oppler, S. H., \& Sager, C. E. (1993). A theory of performance. In N. Schmitt, \& W. C. Borman (Eds.), Personnel selection in organizations (pp. 35-70). San Francisco: Jossey-Bass.

Caruso, D. R., \& Salovey, P. (2004). The emotionally intelligent manager: How to develop and use the four key emotional skills of leadership. John Wiley \& Sons.

Cherniss, C. (2001). EI and organizational effectiveness. The emotionally intelligent workplace: How to select for, measure, and improve EI in individuals, groups, and organizations (pp. 3-12).

Chirasha, V. (2013). Management of discipline for good performance: A theoretical perspective. Online Journal of Social Sciences Research, 2(7), 214-219.

Conti, R., Amabile, T. M., \& Pollak, S. (1995). The positive impact of creative activity: Effects of creative task engagement and motivational focus on college students' learning. Personality and Social Psychology Bulletin, 21, 1107-1116.

Côté, S., \& Miners, C. T. (2006). EI, cognitive intelligence, and JP. Administrative Science Quarterly, 51(1), 1-28.

Czepiel, J. A., Solomon, M. R., \& Surprenant, C. F. (1985). The service encounter: Managing employee/customer interaction in service business. Lexington, M.A.: Lexington Books.

Deeter-Schmelz, D. R., \& Sojka, J. Z. (2003). Developing effective salespeople: Exploring the link between EI and sales performance. International Journal of Organizational Analysis, 11(3), 211-220.

Dulewicz, V., \& Higgs, M. (2000). EI-A review and evaluation study. Journal of Managerial Psychology, 15(4), 341-372.

Dulewicz, V., \& Higgs, M. (2004). Can EI be developed?. The International Journal of Human Resource Management, 15(1), 95-111.

Fisher, C. D., \& Ashkanasy, N. M. (2000). The emerging role of emotions in work life: An introduction. Journal of Organizational Behavior, 21(2), 123-129.

Ganji, M. (2011). EI. Tehran: Savalan.

Gardner, H., \& Hatch, T. (1989). Educational implications of the theory of multiple intelligences. Educational Researcher, 18(8), 4-10.

Goleman, D. (1998). Working with EI. Random House Digital, Inc..

Grote, R. C. (2002). The performance appraisal question and answer book: A survival guide for managers. Amacom.

Guy, M. E., \& Lee, H. J. (2013). How EI mediates emotional labor in public service jobs. Public Administration Review, 64(3), 289-298.

Guzzo, R. A., \& Dickson, M. W. (1996). Teams in organizations: Recent research on performance and effectiveness. Annual Review of Psychology, 47(1), 307-338.

Halbesleben, J. R., \& Bowler, W. M. (2007). Emotional exhaustion and JP: The mediating role of motivation. Journal of Applied Psychology, 92(1), 93.

Hartline, M. D., Maxham III, J. G., \& McKee, D. O. (2000). Corridors of influence in the dissemination of customer-oriented strategy to customer contact service employees. Journal of Marketing, 64(2), 35-50.

Hasanzadeh, R. (2009). EI. Tehran: Ravan

Hult, G. T. M., Hurley, R. F., \& Knight, G. A. (2004). Innovativeness: Its antecedents and impact on business performance. Industrial Marketing Management, 33(5), 429-438.

Ivancevich, J. M., Konopaske, R., \& Matteson, M. T. (2005). Organizational behavior and management (7th ed.). Boston: McGraw-Hill Irwin.

Jacques, E. T. (2009). The relationships between EI and the academic performance and selection of a major of college students. ProQuest.

Karatepe, O. M., \& Uludag, O. (2008). Role stress, burnout and their effects on frontline hotel employees' JP: evidence from Northern Cyprus. International Journal of Tourism Research, 10(2), 111-126. 
Karau, S. J., \& Williams, K. D. (2001). Understanding individual motivation in groups: The collective effort model. In M. E. Turner (Ed.), Groups at work: Advances in theory and research (113-141). Mahwah, N.J.: Lawrence Erlbaum.

Kiely, J. A. (2005). Emotions in business-to-business service relationships. The Service Industries Journal, 25(3), 373-390.

Konopaske, R., Matteson, M., \& Ivancevich, M. T. (2005). Organizational behaviour and management. Boston McGrow Hill.

Kotter, J. (2006). Customer intelligence: An HBR insight centre. Harvard Business Review.

Law, K. S., Wong, C. S., \& Song, L. J. (2004). The construct and criterion validity of EI and its potential utility for management studies. Journal of Applied Psychology, 89(3), 483.

Liptak, J. J. (2005). Using EI to help college students succeed in the workplace. Journal of Employment Counseling, 42(4), 171-178.

Lopes, P. N., Brackett, M. A., Nezlek, J. B., Schütz, A., Sellin, I., \& Salovey, P. (2004). EI and social interaction. Personality and Social Psychology Bulletin, 30(8), 1018-1034.

Lopes, P. N., Salovey, P., Côté, S., Beers, M., \& Petty, R. E. (2005). Emotion regulation abilities and the quality of social interaction. Emotion, 5(1), 113.

Martinaityte, I., \& Sacramento, C. A. (2013). When creativity enhances sales effectiveness: The moderating role of leader-member exchange. Journal of Organizational Behavior, 34(7), 974-994.

Matthews, G., Zeidner, M., \& Roberts, R. D. (2004). EI: Science and myth. MIT Press.

Matthews, G., Zeidner, M., \& Roberts, R. D. (Eds.). (2007). The science of EI: Knowns and unknowns. Oxford University Press.

Mattila, A. S., \& Enz, C. A. (2002). The role of emotions in service encounters. Journal of Service Research, 4(4), 268-277.

Mayer, J. S., \& Salovey, D. P. (1997). What is EI. In Emotional development and EI: Implications for educators (pp. 3-31). New York: Basic Books.

McLean, L. D. (2005). Organizational culture's influence on creativity and innovation: A review of the literature and implications for human resource development. Advances in Developing Human Resources, 7(2), 226-246.

Mikolajczak, M., Menil, C., \& Luminet, O. (2007). Explaining the protective effect of trait EI regarding occupational stress: Exploration of emotional labour processes. Journal of Research in Personality, 41(5), 1107-1117.

Mumford, S. (2003). Dispositions. Oxford University Press.

Neely, A., Gregory, M., \& Platts, K. (1995). Performance measurement system design: A literature review and research agenda. International Journal of Operations \& Production Management, 15(4), 80-116.

Plucker, J. A., \& Renzulli, J. S. (1999). Psychometric approaches to the study of human creativity. In Handbook of creativity (pp. 35-61). New York: Cambridge.

Paulus, P. (2000). Groups, teams, and creativity: The creative potential of idea-generating groups. Applied Psychology, 49(2), 237-262.

Porter, C. O. (2005). Goal orientation: Effects on backing up behavior, performance, efficacy, and commitment in teams. Journal of Applied Psychology, 90(4), 811.

Pulakos, E. D., Arad, S., Donovan, M. A., \& Plamondon, K. E. (2000). Adaptability in the workplace: Development of a taxonomy of adaptive performance. Journal of Applied Psychology, 85(4), 612.

Rode, J. C., Mooney, C. H., Arthaud-Day, M. L., Near, J. P., Baldwin, T. T., Rubin, R. S., \& Bommer, W. H. (2007). EI and individual performance: Evidence of direct and moderated effects. Journal of Organizational Behavior, 28(4), 399-421.

Rosete, D., \& Ciarrochi, J. (2005). EI and its relationship to workplace performance outcomes of leadership effectiveness. Leadership \& Organization Development Journal, 26(5), 388-399.

Rothmann, S., \& Coetzer, E. P. (2003). The big five personality dimensions and JP. SA Journal of Industrial Psychology, 29(1).

Runco, M. A. (2004). Everyone has creative potential. In Creativity: From potential to realization (pp. 21-30).

Salleh, N. (2010). Correlation between employees' emotion and EI during change in Brunei. Brunei Darussalam Journal of Technology and Commerce, 5(1), 99-104.

Salleh, N. M, \& Clarke, N. (2009). Cultural influences affecting employees' emotional responses to a merger between two banking institution organisations in Brunei: The significance of social identity \& perceived control. The 6th International Critical Management Conference, Warwick Business School (CMS 2009) Conference proceedings, 13-15 July, 2009.

Salleh, N. M., \& Clarke, N. (2010). Developing EI through training. The 11th International Conference in Human Resource Development Research \& Practice across Europe, UFHRD, University of Pecs, June 2010, Hungary.

Salovey, P., \& Mayer, J. D. (1989). EI. Imagination, Cognition and Personality, 9(3), 185-211.

Seibert, S. E., Kraimer, M. L., \& Liden, R. C. (2001). A social capital theory of career success. Academy of Management Journal, 44(2), 219-237. 
Shahhosseini, M., Silong, A. D., Ismaill, I. A., \& Uli, N. J. (2012). The role of EI on JP. International Journal of Business and Social Science, 3(21), 241-246.

Shahzad, K., Sarmad, M., Abbas, M., \& Khan, M. A. (2011). Impact of EI on employee's performance in telecom sector of Pakistan. African Journal of Business Management, 5(4), 1225-1231.

Shalley, C. E., \& Gilson, L. L. (2004). What leaders need to know: A review of social and contextual factors that can foster or hinder creativity. The Leadership Quarterly, 15(1), 33-53.

Shalley, C. E., Zhou, J., \& Oldham, G. R. (2004). The effects of personal and contextual characteristics on creativity: Where should we go from here?. Journal of management, 30(6), 933-958.

Shalley, C. E., Zhou, J., \& Oldham, G. R. (2004). The effects of personal and contextual characteristics on creativity: Where should we go from here?. Journal of Management, 30(6), 933-958.

Sheehan, M. (1999). Workplace bullying: Responding with some EI. International Journal of Manpower, 20(1/2), 57-69.

Slaski, M., \& Cartwright, S. (2003). EI training and its implications for stress, health and performance. Stress and Health, 19(4), 233-239.

Sohn, S. Y., \& Jung, C. S. (2010). Effect of creativity on innovation: Do creativity initiatives have significant impact on innovative performance in Korean firms?. Creativity Research Journal, 22(3), 320-328.

Suh, T., \& Shin, H. (2005). Creativity, JP and their correlates: A comparison between nonprofit and profit-driven organizations. International Journal of Nonprofit and Voluntary Sector Marketing, 10(4), 203-211.

Sy, T., Tram, S., \& O'Hara, L. A. (2006). Relation of employee and manager EI to job satisfaction and performance. Journal of Vocational Behavior, 68(3), 461-473.

Taylor, C. W. (1988). Various approaches to and definitions of creativity. In The nature of creativity (pp. 99-121). Cambridge: Cambridge University Press.

Thompson, L. (2003). Improving the creativity of organizational work groups. The Academy of Management Executive, 17(1), 96-109.

Thorndike, E. L. (1920). Intelligence and its uses. Harper's Magazine, 140, 227-235.

Tischler, L., Biberman, J., \& McKeage, R. (2002). Linking EI, spirituality and workplace performance: Definitions, models and ideas for research. Journal of Managerial Psychology, 17(3), 203-218.

Unsworth, K. (2001). Unpacking creativity. Academy of Management Review, 26(2), 289-297.

Van der Sluis, L. E. (2007). Umbrella for research into human resource development (HRD). Human Resource Development International, 10(1), 99-106.

Van Dyne, L., \& LePine, J. A. (1998). Helping and voice extra-role behaviors: Evidence of construct and predictive validity. Academy of Management Journal, 41(1), 108-119.

Van Rooy, D. L., \& Viswesvaran, C. (2004). EI: A meta-analytic investigation of predictive validity and nomological net. Journal of Vocational Behavior, 65(1), 71-95.

Viswesvaran, C. (1993). Modeling JP: Is there a general factor?. Iowa Univ iowa City.

Viswesvaran, C. (2001). Assessment of individual JP: A review of the past century and a look ahead. Handbook of Industrial, Work and Organizational Psychology, 1, 110-126.

Viswesvaran, C., Schmidt, F. L., \& Ones, D. S. (2005). Is there a general factor in ratings of JP? A meta-analytic framework for disentangling substantive and error influences. Journal of Applied Psychology, 90(1), 108.

Williams, K. D., \& Karau, S. J. (1991). Social loafing and social compensation: The effects of expectations of co-worker performance. Journal of Personality and Social Psychology, 61(4), 570.

Wong, C. S., \& Law, K. S. (2002). The effects of leader and follower ei on performance and attitude: An exploratory study. The Leadership Quarterly, 13, 243-274.

$\mathrm{Wu}$, Y. C. (2011). Job stress and JP among employees in the Taiwanese finance sector: The role of EI. Social Behavior and Personality: An International Journal, 39(1), 21-31.

Xavier, S. (2005). Are you at the top of your game? Checklist for effective leaders. Journal of Business Strategy, 28(3), 35-42.

Zeidner, M., Matthews, G., \& Roberts, R. D. (2004). EI in the workplace: A critical review. Applied Psychology, 53(3), $371-399$.

Zeidner, M., Roberts, R. D., \& Matthews, G. (2008). The science of EI. European Psychologist, 13(1), 64-78.

Zhang, X., \& Bartol, K. M. (2010). Linking empowering leadership and employee creativity: The influence of psychological empowerment, intrinsic motivation, and creative process engagement. Academy of Management Journal, 53(1), 107-128.

Zhou, J., \& George, J. M. (2001). When job dissatisfaction leads to creativity: Encouraging the expression of voice. Academy of Management Journal, 44(4), 682-696. 